\title{
Parents Perceived as Peers: Filial Maturity in Adulthood
}

\author{
Kira S. Birditt · Karen L. Fingerman • \\ Eva S. Lefkowitz $\cdot$ Claire M. Kamp Dush
}

Published online: 12 February 2008

(C) Springer Science+Business Media, LLC 2008

\begin{abstract}
Filial maturity refers to the adult offspring's perception of parents as individuals with past histories and limitations. Three studies were conducted to measure filial maturity and its relational and developmental correlates. Study 1 included adults aged 18-59 to empirically assess filial maturity and its correlates across adulthood. Study 2 examined associations between filial maturity and constructs indicative of emerging adulthood (e.g., emotional autonomy), among people aged 18-24. Study 3 included young and middle-aged adults $(N=158$; ages: $22-49)$ and their parents to assess associations between parents' reports of relationship quality and offspring's filial maturity. Offspring reported greater filial maturity with mothers and with parents with whom they reported greater relationship quality, closeness, and autonomy. Parents who reported greater relationship quality had offspring who reported greater filial maturity. Findings suggest that filial maturity is a dyadic phenomenon that influences parent child relationship quality across the lifespan.
\end{abstract}

\section{K. S. Birditt $(\square)$}

Life Course Development Program, Institute for Social Research, University of Michigan, 426 Thompson St., Ann Arbor, MI 48104, USA

e-mail: kirasb@umich.edu

\section{K. L. Fingerman}

Child Development and Family Studies, Purdue University,

West Lafayette, IN, USA

\section{E. S. Lefkowitz}

Human Development and Family Studies,

Pennsylvania State University, State College, PA, USA

C. M. Kamp Dush

Human Development and Family Science,

The Ohio State University, Columbus, OH 43210, USA
Keywords Parent-child · Filial maturity - Relationship quality $\cdot$ Gender $\cdot$ Autonomy

\section{Introduction}

The parent-child relationship is one of the most long-term and emotion-laden social ties (Bowlby 1980; Cairns 1977; Fingerman 2001a; Noack and Buhl 2004). Although a great deal of research addresses children's and adolescents' perceptions of parents, there is less research examining these issues among young and middle-aged adults. Gerontologists have suggested that offspring experience both increased feelings of autonomy and closeness toward parents across adulthood (Fingerman 2001b). Blenkner (1965) introduced the term "filial maturity" to describe offspring's ability to perceive parents as individuals who have past histories and limitations. Surprisingly, although there is theoretical and qualitative work on filial maturity (Blenkner 1965; Nydegger 1991), there has been less empirical work. It is particularly important to assess filial maturity because parents are living longer and offspring's attaining filial maturity may lead to strong parent-child relationships and increased well-being (Allen et al. 1994; Lang and Schütze 2002).

The aims of the present studies were to: (a) empirically assess filial maturity; (b) examine associations between filial maturity and other parent-child relational constructs (e.g., quality, autonomy); and (c) determine whether parental perceptions of the relationship predict filial maturity.

The Definition of Filial Maturity

Blenkner (1965) described filial maturity as a major task in the relationship between adult offspring and parents, 
whereby the offspring ends the rebellion of adolescence and perceives parents from the perspective of a mature adult rather than a child. The filially mature adult offspring is able to understand the parent as a peer with a past history and limitations. Filial maturity goes beyond the adolescent concept of individuation. According to individuation theory, relationships between parents and children develop from hierarchical to more egalitarian relations over adolescence (Grotevant and Cooper 1986; Youniss and Smollar 1985). During adolescence parents and offspring make efforts to increase autonomy while maintaining feelings of connectedness. This process involves the offspring's making his or her own decisions and deidealizing the parents, but at the same time feeling close and intimate. Autonomy is a precursor to filial maturity, which involves not only separation and intimacy, but also the acceptance of the parent as a peer with imperfections.

Theorists have delineated two dimensions of filial maturity based on Blenkner's (1965) original definition. Nydegger (1991) conducted in-depth qualitative interviews of men (ages: 45-80) and of their adult children (ages: 2050) and found that filial maturity involves two distinct dimensions: accepting that the other party has weaknesses (distancing) and viewing the other as peer-like (comprehending). Distancing entails the child's separating from parents and forming a new life as an adult as well as the child's perceiving the parent objectively as a person with faults. Comprehending occurs subsequent to distancing and refers to the ability to see the parent as an individual with a life history that exists independent of the parentchild relationship. More recently, Fredricksen and Sharlach (1996) further clarified that filial maturity involves the ability to engage in an empathetic, compassionate, and reciprocal parent-child relationship that also includes an awareness of parents' needs and limitations.

It is particularly important to develop a brief empirical measure of filial maturity as the majority of filial maturity studies have relied on qualitative assessments (Fingerman 1997; Lang and Schutze 2002) or measures that are rather lengthy. For example, researchers asked participants to describe changes in the parent-child relationships (Fingerman 1997) or how they could please their parents (Lang and Schütze 2002). Empirical studies have assessed filial maturity with the Louvain Filial Maturity Scale which includes 81 items that assess seven factors including filial love, obligation, helpfulness, help, autonomy, parental consideration, and family solidarity (Marceon 1995). In addition, other studies have used an assessment of filial anxiety as a proxy for filial maturity (Cicirelli 1988; Murray et al. 1995). Therefore, a brief quantitative assessment of filial maturity is warranted, especially to examine the two dimensions of filial maturity and how those dimensions are associated with other developmental and relational variables.
Although Nydegger (1991) stated that filial maturity consists of distancing and comprehending, it is unclear from her theory whether it is important to have high amounts of distancing and comprehending or different combinations, such as high comprehending and moderate distancing. Although distancing may be important for filial maturity, too much focus on faults may suggest a lack of maturity (Allen et al. 1994; Steinberg 2001; Youniss and Smollar 1985). Indeed, research indicates that holding extremely negative feelings about parents hinders filial maturity and, further, that negative feelings increase in adolescence and decrease in young adulthood (Carstensen 1992; Nydegger 1991; Suitor and Pillemer 1987). Because the empirical literature indicates that too much distancing may be indicative of immaturity and poor relationship quality, we also considered other combinations by examining interactions between distancing and comprehending. For example, filial maturity may involve perceiving parents as peers (comprehension) while still retaining a degree of distance in the tie (moderate distancing). In addition, we assessed whether filial maturity varied with offspring's age, the parents' gender, the quality of the relationship, and by the offspring's sense of autonomy or closeness to the parent.

Age

According to theorists, filial maturity may begin in early adulthood and increase across adulthood (Blenkner 1965; Nydegger 1991). Indeed, other aspects of maturity, such as relationship quality and adults' interest in parental health, begin in early adulthood and become increasingly honed by midlife. Several studies have shown that parent-child relationships become more positive and less negative as people age (Hagestad 1984, 1987; Suitor and Pillemer 1987; Umberson 1989). In addition, Hay et al. (2005a) found that even young adults worry about their parents' health. By midlife, adults are surprisingly accurate in reporting their parents' health problems and functional status (Fingerman et al. 2005). We predicted that filial maturity would be positively associated with age.

\section{Gender of Parent}

Individuals may hold differing levels of filial maturity toward one parent (e.g., their mother), but not toward the other (e.g., their father). Nydegger (1991) hypothesized that filial maturity is more likely to occur with mothers than with fathers. This variation in filial maturity may arise because mothers are more invested in their children and consequently spend more time with children than do fathers (Fingerman 2001a; Rossi and Rossi 1990). Mothers may be more likely to share information with their children 
regarding their past histories, which may facilitate filial maturity. We predicted that participants would report greater filial maturity with mothers than with fathers.

\section{Relationship Quality}

The ability to maintain distance and comprehend parents as individuals may be particularly important for relationship quality. Fingerman (1996) examined problems between middle-aged women and their mothers and found that middle-aged women in the highest quality relationships framed relationship problems in terms of their mothers' faults, and accepted these faults. Women in more problematic relationships took their mothers' actions personally and felt impinged upon as a result. These findings suggest that filial maturity may help improve women's relationships with their mothers. Similarly, Lang and Schütze (2002) found that filially mature adults were more likely to spend time with parents for pleasure rather than help. In addition, offspring who are able to accept their parents' faults and to view their parents as individuals may be better suited to cope with their parents' decisions regarding health treatments, hence reducing conflict and increasing relationship quality (Fingerman 2000). Because of the importance of relationship quality, we examined correlations between relationship quality and filial maturity in all three studies. We predicted that more positive and less negative relationships would be associated with greater filial maturity. We also considered whether particular combinations of distancing and comprehending are more highly associated with relationship quality by considering interactions between distancing and comprehending.

In addition, in Study 3, we were able to consider parental perceptions of the quality of the parent-child relationship. It is important for the development of filial maturity that parents have a confiding relationship with their children in which they are able to reveal information about themselves. Thus, parents may hinder the development of filial maturity if they have overly negative views of the relationship and do not confide in their children (Nydegger 1991). Research suggests that it is more normative for parents to have more positive views of the relationship than do their offspring (Rossi and Rossi 1990; Shapiro 2004). We expected that parental perceptions of higher quality relationships would be linked to greater offspring filial maturity. We also considered whether parental views of relationship quality varied by combinations of distancing and comprehending.

\section{Autonomy and Closeness}

Filial maturity is theorized to occur after the adolescent period. Throughout adolescence, offspring grow increasingly autonomous by becoming more able to perceive parents outside of the parental role and as less idealized (Blos 1979; Steinberg 2001; Youniss and Smollar 1985). During this period, however, adolescents also maintain closeness to parents. The achievement of simultaneous closeness and autonomy from parents is sometimes referred to as personal authority (Bray and Harvey 1992) and may precipitate filial maturity. Indeed, closeness may increase subsequent to the push for autonomy in adolescence. Filial maturity goes beyond these constructs to incorporate perceiving parents as peers as well as perceiving the parent as having weaknesses. Thus, we predicted that filial maturity would be associated with greater autonomy, greater closeness, greater individuation, and greater personal authority.

\section{Overview of the Studies}

These three studies: (a) empirically assess filial maturity (i.e., comprehending and distancing), (b) test its association with other related constructs (e.g., personal authority, autonomy), and (c) examine within-family influences (mother's or father's ratings of relationship quality) on filial maturity. Study 1 assessed Nydegger's (1991) two dimensions of filial maturity (distancing, comprehending) among adults aged 18-59. This study also considered correlates of these dimensions of filial maturity (age, gender of parent, and relationship quality). Study 2 examined how filial maturity is associated with relationship quality, autonomy, and closeness among individuals at the transition to adulthood. Study 3 examined associations between offsprings' filial maturity and parents' and offspring's perceptions of relationship quality in young and middle adulthood. Table 1 provides characteristics of the three samples. Each study is followed by a summary of the results with a general discussion at the end.

\section{Study 1}

Participants included 616 participants (339 women, 277 men; ages 18-59) recruited via convenience sampling in U.S. recruitment sites including college courses at a large university, community festivals, and word of mouth.

\section{Procedure}

Participants with two living parents were randomly assigned to complete questionnaires concerning either their mother or father that they either mailed or returned to the research assistants. Participants who had only one living parent completed the survey for that parent. We stratified 
Table 1 Sample description for each study

\begin{tabular}{llll}
\hline & $\begin{array}{l}\text { Study 1 } \\
\text { Ages: } \\
18-59 \\
(N=616)\end{array}$ & $\begin{array}{l}\text { Study 2 } \\
\text { Ages: } \\
18-24 \\
(N=144)\end{array}$ & $\begin{array}{l}\text { Study 3 } \\
\text { Ages: } \\
22-49 \\
(N=158)\end{array}$ \\
\hline $\begin{array}{llll}\text { Offspring age } \\
\quad \text { Mean }\end{array}$ & 27.91 & 20.70 & 34.89 \\
$\quad$ Standard deviation & 11.52 & 1.65 & 7.27 \\
$\quad$ Range & $18-59$ & $18-24$ & $22-49$ \\
Parent's age & & & \\
$\quad$ Mean & & 49.38 & 62.18 \\
$\quad$ Standard deviation & & 5.51 & 9.05 \\
$\quad$ Range & & $30-75$ & $40-84$ \\
Offspring gender & & & \\
$\quad$ Men & .45 & .44 & .48 \\
$\quad$ Women & .55 & .56 & .52 \\
Parent gender & & & .50 \\
$\quad$ Mother & .51 & .50 & .50 \\
Father & .49 & .50 & \\
\hline
\end{tabular}

the distribution of questionnaires pertaining to mother vs. father such that $51 \%$ of adults completed the survey for mother and $49 \%$ completed the questionnaire regarding father. The questionnaire took $15 \mathrm{~min}$, and participants did not receive reimbursement.
Measures

\section{Background Information}

Participants reported their age and gender which was coded as 0 (women), 1 (men).

\section{Filial Maturity}

The initial measure consisted of 21 items designed to assess the two major dimensions of filial maturity discussed by Nydegger: distancing (e.g., "My parent has some really annoying habits") and comprehending ("I think of my parent as more of a friend than a parent"). Our goal was to select those items that best represented the two dimensions for a brief measure of filial maturity. See Table 2 for a complete list of the 21 items. The participants rated their agreement with each item from 1 (strongly disagree) to 4 (strongly agree).

\section{Relationship Quality}

Participants also completed assessments of positive and negative relationship quality. Positive relationship quality was assessed using 8 items from Walker's (1979)

Table 2 Exploratory factor analyses of the 21-item filial maturity measure for Study 1

\begin{tabular}{|c|c|c|c|}
\hline & Comprehending & Distancing & Decision \\
\hline I often tell my parent about my problems and rely on him/her for advice & .77 & .16 & Comprehending \\
\hline It means a lot to me when my parent confides in me & .51 & .23 & Comprehending \\
\hline I think of my parent as more of a friend than a parent & .56 & .18 & Comprehending \\
\hline I share my deepest thoughts and feelings with my parent & .70 & .25 & Comprehending \\
\hline My parent sometimes comes to me for advice about important matters & .48 & -.06 & Comprehending \\
\hline As I grow older, I notice my parent and I have more in common & .59 & .23 & Comprehending \\
\hline Regardless of how much I love my parent, he/she certainly has faults & .22 & -.72 & Distancing \\
\hline My parent is practically perfect (REVERSED) & -.13 & -.72 & Distancing \\
\hline I worry about turning out like my parent & -.15 & -.68 & Distancing \\
\hline My parent has some really annoying habits & -.01 & -.74 & Distancing \\
\hline I prefer to turn to my parent when I have a problem rather than anyone else & 67 & .33 & Low face validity \\
\hline I enjoy hearing about experiences my parent had before I was born & .42 & .23 & Low loadings \\
\hline I do not tell my parent about my problems because I don't want to worry him/her & -.37 & .18 & Low loadings \\
\hline It is important to me that my parent approves of me & .36 & .39 & Indistinct loadings \\
\hline I care about my parent's opinion of me more than other people's opinions of me & .37 & .51 & Indistinct loadings \\
\hline As I've grown older, I feel less dependent on my parent than I used to be & -.21 & -.29 & Low loadings \\
\hline I want to be like my parent some day & .46 & 62 & Indistinct loadings \\
\hline My parent is the person I admire most & .53 & .61 & Indistinct loadings \\
\hline When I visit my parent, I feel like a child again & .19 & .05 & Low loadings \\
\hline My parent's good points certainly outweigh his/her bad points & .38 & .58 & Indistinct loadings \\
\hline My parent is from a different generation, I don't relate to his/her values or life & -.37 & -.37 & Indistinct loadings \\
\hline
\end{tabular}


Attachment Scale. This measure assesses positive feelings about relationships (rather than attachment style) with a 10-point scale from 1 (not at all) to 10 (always; Thompson and Walker 1984). Example items include, "My mother understands me," and "My mother is supportive of me." The alpha coefficient for this scale was .90 .

Negative relationship quality was assessed with an item from surveys of parent/offspring ties: "How often does your mother/father do something to upset you?" (Umberson 1989; Webster and Herzog 1995). The item is rated from 1 (as often as once a week) to 6 (less frequently than once a year). We reversed the items so that higher scores represented more frequent upsets.

\section{Results}

We first conducted a series of exploratory and confirmatory factor analyses to determine which items best represented the two-factor construct of filial maturity. We then examined associations between the filial maturity scores, age, gender, and relationship quality.

We began by conducting a principal components analysis (PCA) with a varimax rotation of the 21 filial maturity items. PCA is a commonly used and accepted procedure for establishing how test items load on different theoretical dimensions (Bryant 2000; Cicerelli 1988). Because theory indicates that there are two dimensions of filial maturity, we constrained the solution to two factors. We considered an item as part of a factor if it had high loadings (approximately .5 or greater) on one-factor and low loadings (approximately .3 or lower) on the other factor (Bryant and Yarnold 1995; Cicerelli 1988). Four items appeared to represent a 'distancing' factor and seven items seemed to represent a 'comprehending' factor (Table 2). We then evaluated each of the 11 items for its face validity. We dropped the item, 'I prefer to turn to my parent when I have a problem rather than anyone else,' because it could be interpreted as an indication of immaturity or dependence on parents rather than comprehending.

We conducted another PCA with the remaining ten items and we found a similar solution with the four items loading on the distancing factor and the remaining six items loading on the comprehending factor (Table 3). We then created mean comprehending and distancing scores by averaging the items for each factor. $\alpha=.76$ for both scales. The correlation between the scales was -.33 , $p<.01$.

Next, we conducted a confirmatory factor analysis of the ten items using AMOS version 6 (Tables 4 and 5). We used the Chi-square statistic, CFI (Comparative Fit Index), TLI (Tuker-Lewis Index), GFI (Goodness-of-Fit Index), and RMSEA (Root Mean Squared Error of Approximation) to determine the adequacy of the model (Browne and Cudeck 1993). For a model with a good fit, the Chi-Square statistic should be nonsignificant. However, Chi-square statistics are highly dependent on sample size, with larger samples tending to produce significant chi-square results (Bryant and Yarnold 1995). Thus, we also considered the CFI, TLI, and GFI for which .90 to .95 represent acceptable-to-good fit and the RMSEA between .05 and .08 indicates an acceptable to good fit (Browne and Cudeck 1993; Bryant and Yarnold 1995). The two-factor model had a good fit $\left(\chi^{2}\right.$ $(n=34)=159.05, \quad p<.001, \quad$ TLI $=.89, \quad$ CFI $=.92$, $\mathrm{GFI}=.95$, RMSEA $=.08)$, especially compared to the one-factor model $\left(\chi^{2} \quad(n=35)=516.53, \quad p<.001\right.$, $\mathrm{TLI}=.59, \mathrm{CFI}=.68, \mathrm{GFI}=.82, \mathrm{RMSEA}=.15) . \mathrm{Next}$, we examined correlations between the comprehending and distancing scales, age of offspring, gender of parent, and relationship quality (positive, negative). As can be seen in
Table 3 Exploratory factor analyses of the 10 filial maturity items for Study 1

\begin{tabular}{lcccc}
\hline & Comprehending & Distancing & Decision \\
\hline $\begin{array}{l}\text { I often tell my parent about my problems and rely on him/ } \\
\text { her for advice }\end{array}$ & .79 & -.10 & Comprehending \\
It means a lot to me when my parent confides in me & .58 & -.13 & Comprehending \\
I think of my parent as more of a friend than a parent & .63 & -.17 & Comprehending \\
I share my deepest thoughts and feelings with my parent & .75 & -.24 & Comprehending \\
My parent sometimes comes to me for advice about & .56 & .07 & Comprehending \\
$\quad$ important matters & & -.11 & Comprehending \\
As I grow older, I notice my parent and I have more in & .63 & .79 & Distancing \\
$\quad$ common & & & \\
Regardless of how much I love my parent, he/she certainly & .11 & .73 & Distancing \\
$\quad$ has faults & -.25 & .68 & Distancing \\
My parent is practically perfect (REVERSED) & -.24 & .80 & Distancing \\
I worry about turning out like my parent & -.11 & & \\
My parent has some really annoying habits & & &
\end{tabular}


Table 4 Unstandardized loadings (Standard Errors) and standardized loadings for 2-factor confirmatory model of filial maturity for Studies 1 through 3

\begin{tabular}{|c|c|c|c|c|c|c|}
\hline & \multicolumn{2}{|l|}{ Study 1} & \multicolumn{2}{|l|}{ Study 2} & \multicolumn{2}{|l|}{ Study 3} \\
\hline & Unstandardized & Standardized & Unstandardized & Standardized & Unstandardized & Standardized \\
\hline \multicolumn{7}{|l|}{ Distancing } \\
\hline Parent has faults & $.83(.07)$ & .61 & $.78(.17)$ & .55 & $1.21(.23)$ & .67 \\
\hline Parent is perfect & $1.09(.09)$ & .69 & $1.14(.22)$ & .64 & $.91(.21)$ & .47 \\
\hline Parent has bad habits & $1.14(.09)$ & .73 & $1.05(.20)$ & .71 & $1.21(.24)$ & .62 \\
\hline Worry about turning out like parent & $1.00(-)$ & .63 & $1.00(-)$ & .58 & $1.00(-)$ & .60 \\
\hline \multicolumn{7}{|l|}{ Comprehending } \\
\hline Parent is friend & $1.16(.12)$ & .56 & $1.16(.25)$ & .53 & $.63(.12)$ & .48 \\
\hline Rely on parent for advice & $1.76(.16)$ & .74 & $2.03(.37)$ & .76 & $.77(.11)$ & .66 \\
\hline Share feelings with parent & $1.75(.15)$ & .78 & $2.08(.36)$ & .88 & $1.00(-)$ & .79 \\
\hline Parent confides & $.92(.11)$ & .48 & $.61(.21)$ & .29 & $.57(.09)$ & .56 \\
\hline Comes to me for advice & $.93(.12)$ & .42 & $1.28(.29)$ & .50 & $.85(.12)$ & .67 \\
\hline Have a lot in common & $1.00(-)$ & .51 & $1.00(-)$ & .50 & - & - \\
\hline
\end{tabular}

Table 5 Correlations between filial maturity scales, age, gender, and parent-child relationship assessments in Studies 1 and 2
$* p<.05 ; * * p<.01$

\begin{tabular}{|c|c|c|c|c|}
\hline & \multicolumn{2}{|l|}{ Study 1} & \multicolumn{2}{|l|}{ Study 2} \\
\hline & Comprehending & Distancing & Comprehending & Distancing \\
\hline Participants' age & -.05 & .03 & $.28 * *$ & .01 \\
\hline Parent's gender & $-.18 * *$ & -.03 & $-.32 * *$ & -.01 \\
\hline Negative quality & $-.12 * *$ & $.45^{* *}$ & $-.27 * *$ & $.53 * *$ \\
\hline Positive quality & $.50 * *$ & $-.47 * *$ & $.58 * *$ & $-.39 * *$ \\
\hline \multicolumn{5}{|l|}{ Autonomy } \\
\hline Parents as people & - & - & $-.20 *$ & $.33 * *$ \\
\hline Deidealization & - & - & $-.37 * *$ & $.49 * *$ \\
\hline Closeness (IOS) & - & - & $.59 * *$ & $-.38 * *$ \\
\hline Individuation & - & - & $.23 * *$ & $-.37 * *$ \\
\hline Personal authority & - & - & $.49 * *$ & $-.11 * *$ \\
\hline
\end{tabular}

Table 5, participants reported greater comprehending and less distancing when they perceived their parents as more positive and less negative. Participants who reported on mothers reported greater comprehending than those reporting on fathers.

However, because filial maturity is meant to be a combination of distancing and comprehending, we also conducted regression analyses with comprehending, distancing and the interaction between them as predictors of positive and negative relationship quality. There was a significant interaction between comprehending and distancing when predicting positive relationship quality ( $B=3.34, \mathrm{SE}=.75, p<.001$, adjusted $\left.R^{2}=.37\right)$. To examine the interaction, we divided the distancing and comprehending scores into low, medium, and high scores using the $25 \mathrm{th}, 50^{\text {th }}$, and 75 th percentiles and plotted relationship quality by the two categorical variables. See Fig. 1 for the interaction effect. The interaction indicates that high comprehending along with moderate-to-low perceptions of distancing is associated with the greatest positive relationship quality.

In sum, we empirically assessed filial maturity with a four-item distancing and a six-item comprehending scale. The scales had good internal consistency and reliability, and loaded well on the two dimensions of filial maturity. In addition, as expected, participants who reported on mothers had higher scores on the measure of filial maturity than did participants who reported on fathers. Participants also reported greater comprehending in parental relationships they rated as more positive and less negative. Finally, high comprehending combined with moderate-to-low perceptions of distancing was associated with the highest quality relationships. Thus, it appears that filial maturity may be composed of moderate-to-low distancing coupled with high comprehending rather than high levels of distancing and comprehending. 


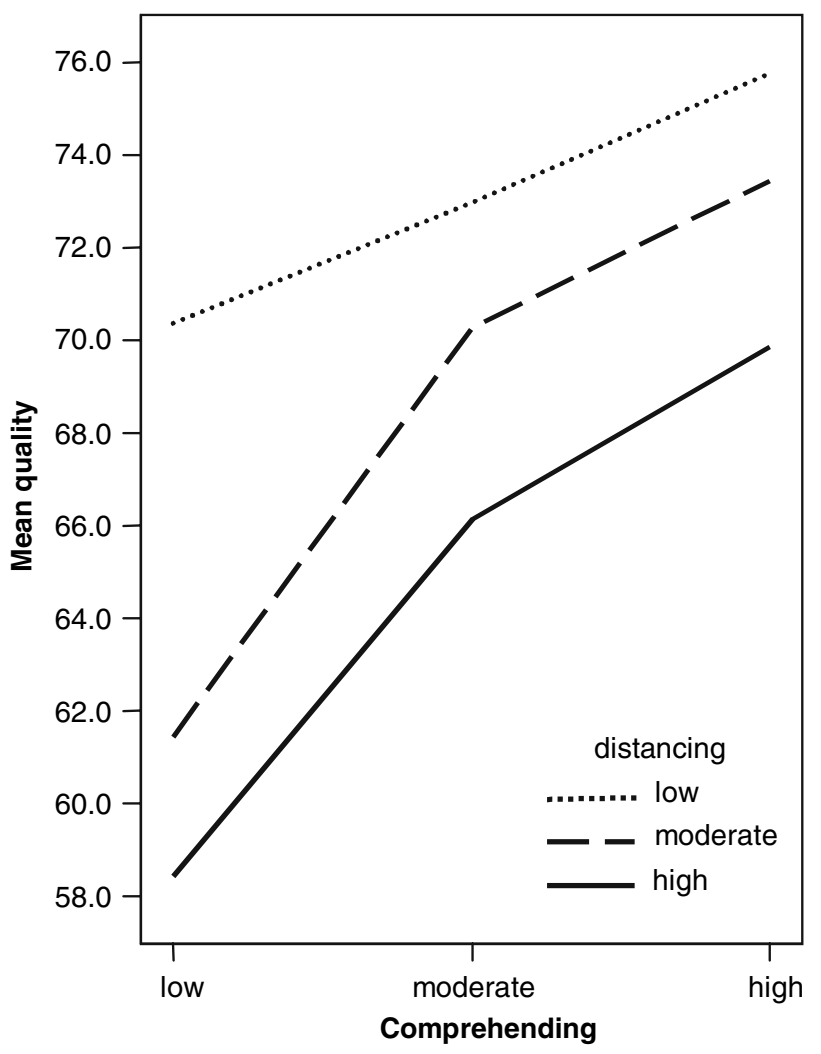

Fig. 1 Offspring reports of positive relationship quality as a function of comprehending and distancing

\section{Study 2}

This study was conducted with a young adult sample to replicate findings from Study 1 and to examine whether filial maturity is associated with indicators of development in adolescence and the transition to adulthood including autonomy, closeness, individuation, and personal authority. As in Study 1, we also examined age, gender of parent, and relationship quality.

\section{Participants}

Participants included 144 (62 men, 82 women) college students (ages 18-24). Participants randomly completed measures regarding either their mother (72) or father (72; Table 1). Participants were recruited in human development, psychology, science classes, and via word of mouth.

\section{Measures}

Participants completed the same measures as in Study 1, as well as assessments of autonomy, closeness, individuation, and personal authority.

\section{Emotional Autonomy}

The complete 20-item measure is composed of four scales (Steinberg and Silverberg 1986). For the purpose of this study, we examined the Parents as People Scale (6 items) and the Parental Deidealization scale (5 items). Perception of parents as people is the extent to which participants perceive their parents as individuals outside of the parental role (e.g., "I might be surprised to see how my parents act at a party"), whereas deidealization is the perception that the parents are imperfect (e.g., "My parents hardly ever make mistakes," reverse coded). Alpha coefficients for the parents as people and deidealization scales were .74 and.75, respectively.

\section{Inclusion of Other in the Self (IOS) Scale}

This measure of closeness assesses the extent to which people feel interpersonally interconnected or that the partner is part of one's self. The measure consists of one item, which asks participants to select a Venn diagram to represent their relationship with their parent (Aron et al. 1992; Aron et al. 1991). The diagrams range from two separate circles representing the participant and the parent to two almost completely overlapping circles. We added 1 additional diagram to the original seven choices to represent an even more distant relationship (two circles apart). The choices include 1 (two circles apart), 2 (circles touching), 3 (small overlap), 4 (1/4 overlap), 5 (1/2 overlap), 6 (3/4 overlap), 7 (more than 3/4 overlap), 8 (almost total overlap). Higher numbers represent greater feelings of closeness.

\section{Personal Authority in the Family Questionnaire (PAFS} version C)

We included two scales from this measure, including individuation (8 items) and personal authority (18 items; Bray and Harvey 1992; Williamson et al. 1985). Individuation refers to the extent to which the child is differentiated from the parent (e.g., "I am usually able to disagree with my parent without losing my temper"). Participants rate their agreement with each item from 1 (strongly disagree) to 5 (strongly agree; $\alpha=.70$ ). Personal authority refers to the ability to have an intimate and simultaneously individuated relationship with parents [e.g., "How comfortable are you talking to your father and mother about specific mistakes or wrong decisions which he/she made in the past and would like to do again differently (e.g. marriage, marriage partner, occupation, etc.)?"]. Participants rated each item from 1 (very 
uncomfortable) to 5 (very comfortable; $\alpha=.82$ ). Individuation and personal authority are examined separately.

Results

We confirmed the factor structure with a confirmatory factor analysis (Table 4); the two-factor model provided an excellent fit $\left(\chi^{2}(n=34)=54.01, p<05\right.$, TLI $=.92$, $\mathrm{CFI}=.94$, GFI $=.93$, RMSEA $=.06)$ compared with the one factor model $\left(\chi^{2} \quad(n=35)=122.48, \quad p<.001\right.$, $\mathrm{TLI}=.65, \mathrm{CFI}=.73, \mathrm{GFI}=.83$, $\mathrm{RMSEA}=.13) . \mathrm{We}$ then created mean comprehending and distancing scores by averaging the items for each factor. Next we calculated correlations among comprehending, distancing, autonomy (parents as people, deidealization), closeness (IOS), individuation, personal authority, age, gender of parent, and relationship quality (positive, negative; Table 5). The comprehending and distancing scales for filial maturity were significantly correlated $(r=-.34, p<.05)$, and internally consistent $\alpha=.75$ and $\alpha=.71$, respectively. As predicted, participants reported greater comprehending when they reported greater personal authority, greater individuation, when they were older, when they reported on their mothers, and when they reported greater relationship quality (more positive and less negative). In addition, participants reported greater distancing when they reported greater autonomy from parents (higher scores on scales for perceptions of parents as people and for deidealization).

We also found some unexpected associations. Participants reported greater comprehending when they reported less autonomy from parents (lower scores on the scales for parents as people and for deidealization). Similar to Study 1, participants reported greater distancing when they reported lower relationship quality (less positive and more negative) and less closeness.

Next, we examined positive and negative relationship quality as a function of distancing, comprehending, and the interaction of distancing $\times$ comprehending with linear regression analyses. The main effects for distancing and comprehending fit the pattern evident in the bivariate associations in Table 5, and the interaction for distancing $\times$ comprehending was not significant.

In sum, this study revealed that the 10-item filial maturity measure had the same factor structure and good internal reliability when used in an independent sample of college students. In addition, the comprehending scale demonstrated expected associations with age, gender of parent, relationship quality, and adolescent developmental achievements including personal authority and individuation. Because the distancing scale was associated with lower relationship quality and closeness and comprehending was associated with less autonomy, it is possible that distancing and autonomy peak and decrease prior to comprehending. Too much distancing may actually hinder the development of comprehending. Thus, high comprehending and moderate distancing may be the most indicative of filial maturity.

\section{Study 3}

The purpose of this study was to understand how parental and offspring perceptions of relationship quality and closeness are associated with filial maturity in adulthood. This study included parental as well as offspring perceptions of relationship quality and closeness. It is important to examine within-family associations between variables, not only to establish validity but also to examine how parents and children may influence one another.

\section{Participants}

Participants were from the Adult Family Study (Fingerman et al. 2004), which included 213 family triads (mother, father, and child) who completed individual phone interviews. The triads consisted of adult offspring (ages: 22-49; $48 \%$ men) and their mothers and fathers (ages: 40-84). The sampling relied on a randomized stratified procedure by age, gender, and race. One-third of participants were Black and the remaining participants were White. Of the 213 triads, 158 completed in-home interviews that included a filial maturity measure and assessments of relationship quality. Both parents completed measures regarding the quality of their relationship with the target offspring. Half of the offspring randomly completed filial maturity measures regarding their mother $(n=79)$ whereas the other half completed the questionnaire regarding their father $(n=79)$.

\section{Measures}

Participants completed a nine-item filial maturity measure, and assessments of demographics and closeness used in Study 2 (IOS; Aron et al. 1991). Due to a clerical error, the comprehending item, "As I get older, my parent and I have more in common," was omitted. The fit of the model changed very little with the item omitted. Gender of parent was coded as 0 (women), 1 (men) and race was coded as 0 (White), 1 (Black).

\section{Relationship Quality}

In this study we used a different measure of quality than in studies 1 and 2 to assure the validity of the association 
between quality and filial maturity. Participants completed a 14-item scale to assess the positive and negative qualities of their relationship, the Parent Adult Relationship Questionnaire (Hay et al. 2005b). Respondents indicated how often in the past 12 months their mother/father/child engaged in a series of positive (e.g., acted warm) and negative (e.g., behaved insensitively) behaviors ranging from 1 (never) to 5 (always). Six items assess positive quality ( $\alpha=.78$ to .87 ) and 8 items assess negative quality $(\alpha=.78$ to .83$)$. The items are based on an instrument regarding positive and negative interactions developed by Newsom et al. (2000).

\section{Results}

We conducted confirmatory factor analyses followed by correlations between filial maturity, age of offspring, gender of parent, and relationship quality as reported by offspring and their parents (Table 6). According to confirmatory factor analyses (Table 4), the model provided an excellent fit $\left(\chi^{2}(n=31)=92.26, p=.20 ;\right.$ TLI $=.97$, $\mathrm{CFI}=.98, \mathrm{GFI}=.96$, RMSEA $=.04$, especially compared to the one-factor model $\left(\chi^{2}(n=27)=93.03\right.$, $p<.001$; TLI $=.69, \mathrm{CFI}=.77$, GFI $=.87$, RMSEA $=$ $.13, \alpha=.74$ for distancing and .77 for comprehending). We then created mean comprehending and distancing scores by averaging the items for each factor. Because mother, father, and offspring completed the relationship quality and closeness measures, the correlations are examined separately for each of the four reports (father report of child, mother report of child, child report of father, child report of mother).

Offspring reported greater comprehending with parents they rated as more positive, less negative, and closer. Offspring's scores for comprehending parent were also associated with greater parent reports of positive relations as well as greater closeness. In addition, we found associations between distancing and other constructs that were similar to studies 1 and 2. In particular, offspring reported greater distancing when they rated their parents as more negative, less positive, and less close. Distancing was also associated with parental reports of greater negativity, less closeness, and less positivity.

Because filial maturity theoretically comprises a combination of distancing and comprehending, we also examined relationship quality as a function of comprehending, distancing, and the interaction between the two with linear regression analyses. We found a marginally significant interaction between comprehending and distancing when predicting offspring reports of the positive qualities of the father-child relationship $(B=1.53, S E=$ $.78, p=.05$, adjusted $R^{2}=.43$ ) and a significant interaction when predicting father reports of the positive qualities of the relationship $(B=1.56, S E=.71, p<.001$, adjusted $\left.R^{2}=.10\right)$. The interactions are presented in Figs. 2 and 3 . Offspring reports of greater comprehending and less distancing with fathers are associated with offspring reports of the greatest positive relations. However, most interestingly, the greatest father reports of positivity occur with moderate comprehending and distancing.

Overall, this study demonstrated that filial maturity does not appear to be composed of high distancing and comprehending but low/ moderate distancing and comprehending. Parental as well as child perceptions of positive parent-child relationships were associated with offspring's filial maturity.

\section{General Discussion}

Overall, these studies used a brief measure to empirically assess filial maturity among people from young-to-middle adulthood. Filial maturity refers to the offspring's ability to perceive his/her parents as individuals with past histories and weaknesses. It appears that greater filial maturity is
Table 6 Correlations among filial maturity and offspring and parent reports of relationship quality in Study 3

$* p<.05 ; * * p<.01$

\begin{tabular}{|c|c|c|c|c|}
\hline & \multicolumn{2}{|l|}{ Mother } & \multicolumn{2}{|l|}{ Father } \\
\hline & Distancing & Comprehending & Distancing & Comprehending \\
\hline Age of offspring & -.09 & -.04 & .13 & -.18 \\
\hline Race & .03 & -.13 & -.07 & -.02 \\
\hline \multicolumn{5}{|l|}{ Child reports } \\
\hline Positive relations & $-.40 * *$ & $.43^{* *}$ & $-.49 * *$ & $.57 * *$ \\
\hline Negative relations & $.50 * *$ & -.11 & $.54 * *$ & $-.29 *$ \\
\hline Closeness (IOS) & $-.28^{*}$ & $.46^{* *}$ & $-.57 * *$ & $.55 * *$ \\
\hline \multicolumn{5}{|l|}{ Parent reports } \\
\hline Positive relations & $-.23 *$ & $.24 *$ & -.16 & $.28^{*}$ \\
\hline Negative relations & $.41 * *$ & -.15 & $.26 *$ & -.10 \\
\hline Closeness (IOS) & -.21 & $.34 * *$ & $-.31 * *$ & $.35^{* *}$ \\
\hline
\end{tabular}




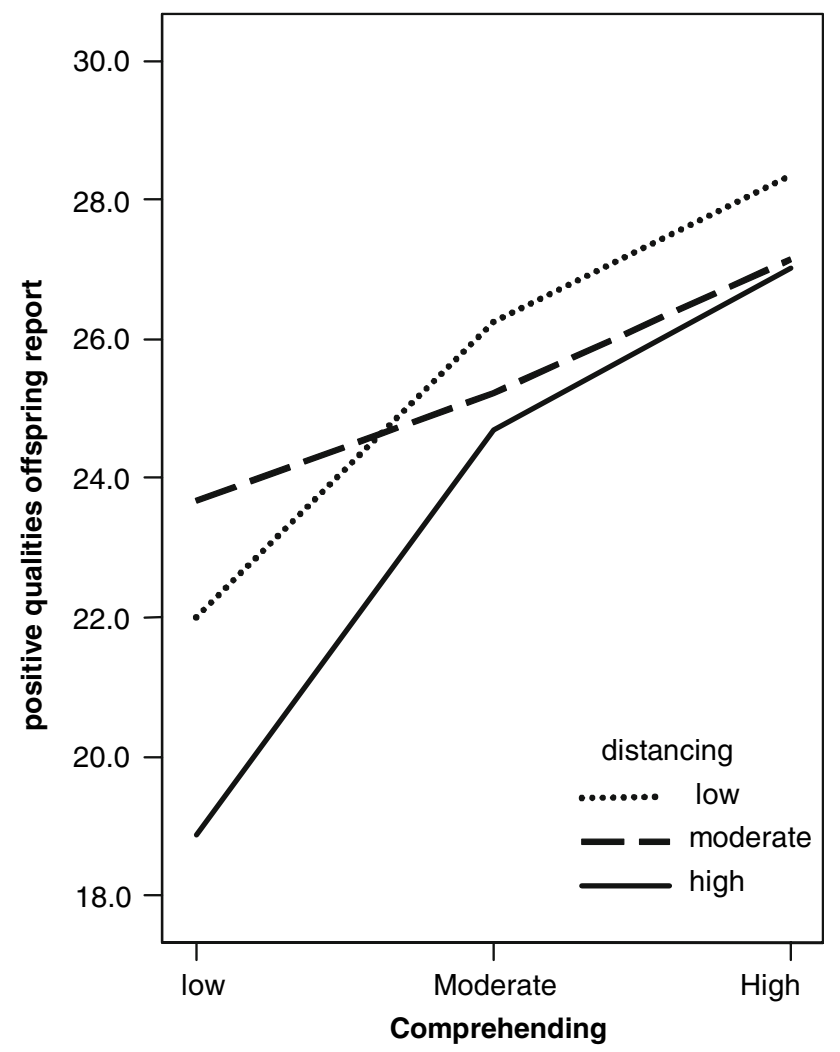

Fig. 2 Offspring reports of positive relationship quality with father as a function of comprehending and distancing

composed of low-to-moderate distancing and high comprehending. Too much distancing may hinder comprehending and distancing may peak before comprehending and then decrease, similar to autonomy. We outline below the associations between comprehending, distancing, age, gender, relationship quality, autonomy, and individuation.

\section{Age and Gender}

We had predicted that older participants would report greater filial maturity than younger participants. As expected, among young adults in Study 2, older offspring reported greater comprehending. However, in the samples that included middle-aged adults (Studies 1 and 3), we found no association between age and filial maturity. It is possible that filial maturity increases initially in young adulthood but that during middle adulthood it is associated with processes that are not developmental, but are more relational such as the type of relationship (e.g., mother, father), quality, and closeness. There were no associations between age and distancing.

Indeed, as hypothesized, participants who rated filial maturity regarding their mothers reported greater comprehending than those who rated their fathers. Perhaps the

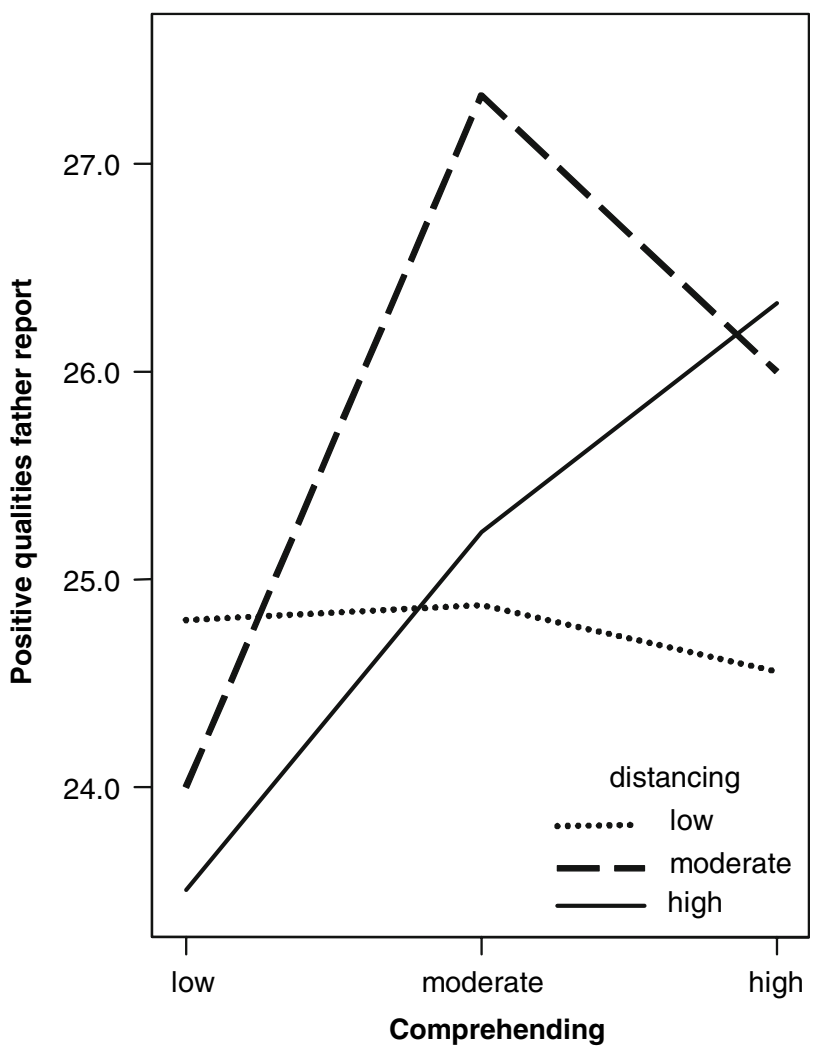

Fig. 3 Father reports of positive relationship quality as a function of comprehending and distancing

greater closeness of the mother-child relationship (Fingerman 2001a; Rossi and Rossi 1990) also involves mothers sharing information regarding their weaknesses and past histories, thus assisting in the development of filial maturity. Likewise, it is possible that in closer relationships, individuals are better able to comprehend one another. Gender and distancing were not significantly associated.

\section{Relationship Quality}

As predicted, comprehending is linked with better quality parent-child relations in young and middle adulthood. Offspring who rated their relations with parents as more positive and less negative reported more comprehending. Parental perceptions of greater positive and less negative relations with offspring were also associated with greater comprehending.

These findings are consistent with research demonstrating that adults who accept parents' faults have more positive and less negative parent child relationships (Fingerman 2000; Suitor and Pillemer 1987, 1988; Umberson 1989). There may be a bi-directional association between relationship quality and filial maturity with greater filial maturity leading to higher quality relations and higher quality relations helping people develop more mature perceptions. 
Unlike what we predicted, distancing was associated with less positive and more negative relations between parents and children in all three studies. It appears that high distancing is detrimental for relationships and that it may hinder comprehending. This is consistent with research indicating that highly negative views of the relationship are detrimental for filial maturity and that negativity in the relationship decreases as people develop (Carstensen 1992; Nydegger 1991; Suitor and Pillemer 1988). It is possible that people experience distancing and autonomy first, and that as these feelings subside they can achieve comprehending.

Interestingly, specific combinations of comprehending and distancing were predictive of relationship quality. In Study 1, we found that low-to-moderate distancing along with high comprehending predicted the greatest relationship quality. In Study 3, we found a similar result when examining participants' reports of positive relations with fathers. Those who reported the greatest comprehending and least distancing also reported high relationship quality. Father reports of positive relations, however, were greatest for offspring who reported high comprehending and high distancing, or moderate comprehending and moderate distancing. Distancing in the father-child relationship may be important for fathers to feel comfortable in the tie.

\section{Autonomy and Closeness}

Further, we found expected associations between filial maturity and reports of closeness, individuation, and personal authority. Offspring and parents who reported greater closeness in the parent-child relationship also reported greater comprehending. In addition, people were more likely to report comprehending when they reported greater individuation and personal authority and offspring who reported greater distancing reported greater autonomy from parents. However, participants reported greater comprehending of parents when they reported less autonomy from parents. It is possible that these perceptions of the parent occur at different times; it is important to first distance oneself and become autonomous from parents, and once those feelings subside the individual is able to perceive parents as peers.

\section{Directions for Future Research}

Limitations in the current studies should be addressed in future research. The use of self-report assessments of relationship quality may be problematic because of socially desirable responding; offspring reported on their own filial maturity and relationship quality. We addressed this issue to some extent in Study 3 in which we found that filial maturity was also associated with parents' reports of relationship quality. Still, future research might enhance an understanding of the association between filial maturity and relationship quality by using behavioral measures of quality, such as observing conflict and the expression of positive affect between parents and children. In addition, because research indicates that relationship quality is associated with better well-being (Shaw et al. 2004; Stimpson et al. 2005), future studies should also examine longitudinal associations among filial maturity, relationship quality, and well-being. In particular, longitudinal research should assess the patterns of distancing and comprehending over time to determine if there is a peak in distancing followed by the development of comprehending.

In addition, Nydegger (1991) suggested that filial maturity is more likely to occur when parents have also reached a state of 'parental maturity.' Further research should assess whether the filial maturity measure can also be adapted to examine parental maturity.

Overall, this study makes a significant contribution to the literature by empirically examining the dimensions of filial maturity and assessing its correlates. We determined that filial maturity is most likely composed of high comprehending and moderate distancing. In addition, filial maturity is associated with better quality relationships according to both offspring and their parents. This study indicates that filial maturity is an intriguing adult developmental phenomenon that needs a great deal of further research. It is most likely important to develop filial maturity to have positive and productive parent-child relationships in adulthood, for both offspring and their parents. Further research should examine how the dimensions of filial maturity change over time.

\section{References}

Allen, J. P., Hauser, S. T., Bell, K. L., \& O’Connor, T. G. (1994). Longitudinal assessment of autonomy and relatedness in adolescent-family interactions as predictors of adolescent ego development and self-esteem. Child Development, 65, 179-194.

Aron, A., Aron, E. N., \& Smollan, D. (1992). Inclusion of other in the self scale and the structure of interpersonal closeness. Journal of Personality \& Social Psychology, 63, 596-612.

Aron, A., Aron, E. N., Tudor, M., \& Nelson, G. (1991). Close relationships as including other in the self. Journal of Personality \& Social Psychology, 60, 241-253.

Blenkner, M. (1965). Social work and family relations in later life with some thoughts on filial maturity. In E. Shanas \& G. F. Streib (Eds.) Social structure and the family: Generational relations (pp. 46-59). Englewood Cliffs, NJ: Prentice Hall, Inc.

Blos, P. (1979). The adolescent passage. New York: International Universities Press.

Bowlby, J. (1980). Attachment and loss: Vol. 1. Attachment. New York: Basic Books. 
Bray, J. H., \& Harvey, D. M. (1992). Intimacy and individuation in young adults: development of the young adult version of the personal authority in the family system questionnaire. Journal of Family Psychology, 6, 152-163.

Browne, M. W., \& Cudeck, R. (1993). Alternative ways of assessing model fit. In K. A. Bollen \& J. S. Long (Eds.), Testing structural equation models. Newbury Park: Sage Publications.

Bryant, F. B. (2000). Assessing the validity of measurement. In L. G. Grimm \& P. R. Yarnold (Eds.). Reading and understanding more multivariate statistics. Washington, DC: American Psychological Association.

Bryant, F. B., \& Yarnold, P. R. (1995). Principal-components analysis and exploratory and confirmatory factor analysis. In L.G. Grimm \& P.R. Yarnold (Eds.), Reading and understanding multivariate statistics (pp. 99-136). Washington, DC: American Psychological Association.

Cairns, R. B. (1977). Beyond social attachment. The dynamics of interactional development. In T. Alloway, P. Pliner, \& L. Krames (Eds.), Attachment behavior (pp. 1-24). New York: Plenum.

Carstensen, L. L. (1992). Social and emotional patterns in adulthood: Support for socioemotional selectivity theory. Psychology and Aging, 7, 331-338.

Cicerelli, V. G. (1988). A measure of filial anxiety regarding anticipated care of elderly parents. The Gerontologist, 28, 478481.

Fingerman, K. L. (1996). Sources of tension in the aging mother and adult daughter relationship. Psychology and Aging, 11, 591606.

Fingerman, K. L. (1997). Being more than a daughter: Middle-aged women's conceptions of their mothers. Journal of Women and Aging, 9, 55-72.

Fingerman, K. L. (2000). We had a nice little chat: Age and generational differences in mothers' and daughters' descriptions of enjoyable visits. Journals of Gerontology: Psychological Sciences, 55, P95-P106.

Fingerman, K. L. (2001a). Aging mothers and their adult daughters; A study in mixed emotions. New York: Springer Publishers.

Fingerman, K. L. (2001b). The paradox of a distant closeness: Intimacy in parent/child ties. Generations (Special Edition: Perspectives on Intimacy), 25, 26-33.

Fingerman, K. L., Lefkowitz, E. S., \& Hay, E. L., (2004). The adult family study. West Lafayette, IN: Purdue University.

Fingerman, K. L., Hay, E. L., Kamp Dush, C.M., Cichy, K. E., \& Hosterman, S. (2005). Role revisions: Parents' and offspring's perceptions of change and continuity in later life. Manuscript submitted for publication.

Fredricksen, K. I., \& Sharlach, A. E. (1996). Filial maturity: Analysis and reconceptualization. Journal of Adult Development, 3, 183191.

Hagestad, G. O. (1984). Multigenerational families, socialization , support, and strain. In V. Garms-Homolova, E. M. Hoerning, \& D. Schaeffer (Eds.), Intergenerational relationships (pp. 105114). Lewiston, NY: C. J. Hogrefe, Inc.

Hagestad, G. O. (1987). Parent-child relations in later life: Trends, gaps in past research. In J. B. Lancaster, J. Altmann, A. S. Rossi, \& L. R. Sherrod (Eds.), Parenting across the lifespan (pp. 405433). New York: Aldine De Gruyter.

Hay, E. L., Fingerman, K. L., \& Lefkowitz, E. S. (2005a). The experience of worry in the parent and adult offspring relationship. Manuscript submitted for publication.

Hay, E. L., Fingerman, K. L., \& Lefkowitz, E. L. (2005b). The Parent-Adult Relationship Quality (PARQ) Scale: A measure of positive and negative qualities in intergenerational relationships. Manuscript in preparation.

Grotevant, H. D., \& Cooper, C.R. (1986). Individuation in family relationships: A perspective on individual differences in the development of identity and role-taking skill in adolescence. Human Development, 29, 82-100.

Lang, F. R., \& Schütze, Y. (2002). Adult children's supportive behaviors and older parents' subjective well-being-a developmental perspective on intergenerational relationships. Journal of Social Issues, 58, 661-680.

Marcoen, A. (1995). Filial maturity of middle aged adult children in the context of parental care: Model and measures. Journal of Adult Development, 2, 125-136.

Murray, P. D., Lowe, J. D., \& Horne, H. L. (1995). Assessing filial maturity through the use of the filial anxiety scale. The Journal of Psychology, 129, 519-529.

Newsom, J. T., Morgan, D. L., Nishishiba, M., \& Rook, K. S. (2000, November). Development of new comparable measures of negative and positive social exchanges. Poster presented at the Gerontological Society of America annual meeting, Washington, DC.

Noack, P., \& Buhl, H. M. (2004). Child-parent relationships. In F. R. Lang \& K. L. Fingerman (Eds.), Growing together. Personal relationships across the lifespan (pp. 45-75). Cambridge: University Press.

Nydegger, C. N. (1991). The development of paternal and filial maturity. In K. A. Pillemer \& K. McCartney (Eds.), Parent-child relations throughout life (pp. 93-112). Hillsdale, NJ: Lawrence Erlbaum Associates.

Rossi, A. S., \& Rossi, P. H. (1990). Of human bonding. Parent-child relations across the lifecourse. New York: De Gruyter.

Shapiro, A. (2004). Revisiting the generation gap: Exploring the relationships of parent/adult-child dyads. International Journal of Aging and Human Development, 58, 127-2004.

Shaw, B. A., Krause, N., Chatters, L. M., Connell, C. M., \& IngersollDayton, B. (2004). Emotional support from parents early in life, aging, and health. Psychology and Aging, 19, 4-12.

Steinberg, L. (2001). We know some things: Parent-adolescent relationships in retrospect and prospect. Journal of Research on Adolescence, 11, 1-19.

Steinberg, L., \& Silverberg, S. B. (1986). The vicissitudes of autonomy in early adolescence. Child Development, 57, 841-851.

Stimpson, J. P., Tyler, K. A., \& Hoyt, D. R. (2005). Effects of parental rejection and relationship quality on depression among older rural adults. International Journal of Aging and Human Development, 61, 195-210.

Suitor, J. J., \& Pillemer, K. (1987). The presence of adult children: A source of stress for elderly couple's marriages. Journal of Marriage and the Family, 49, 717-725.

Suitor, J. J., \& Pillemer, K. (1988). Explaining intergenerational conflict when adult children and elderly parents live together. Journal of Marriage and the Family, 50, 1037-1047.

Thompson, L., \& Walker, A. J. (1984). Mothers and daughters: Aid patterns and attachment. Journal of Marriage and the Family, 46, 313-322.

Umberson, D. (1989). Relationships with children: Explaining parents' psychological well-being. Journal of Marriage and the Family, 51, 999-1012.

Walker, A. J. (1979). The social networks of young marrieds: Distinguishing among relationship types. Unpublished doctoral dissertation, Pennsylvania State University:.

Webster, P. S., \& Herzog, R. A. (1995). Effects of parental divorce and memories of family problems on relationships between adult children and their parents. Journal of Gerontology: Social Sciences, 50, S24-S34.

Williamson, D. S., Bray, J. H., Harvey, D. M., \& Malone, P. E. (1985). Personal Authority in the Family System Questionnaire Version C. Houston, TX..

Youniss, J., \& Smollar, J. (1985). Adolescent relations with mothers, fathers, and friends. Chicago: The University of Chicago Press. 